\title{
Subsection construction technology of rectangular concrete independent column with super high cross section
}

\author{
Guangjun $\mathrm{Li}^{1,2}$, Tianfang $\mathrm{Mo}^{1,2}$, Ningbo $\mathrm{Xu}^{1,2}$, Weixiong Zhang ${ }^{1,2}$, Hanwen $\mathrm{Lu}^{3 *}$, Deyuan Deng ${ }^{4}$, Mingbo $\mathrm{Yi}^{1,2}$ \\ ${ }^{1}$ China Construction Fourth Engineering Division Corp. Ltd, Guangzhou, Guangdong, 510430, China \\ ${ }^{2}$ China Construction 4th Engineering Bureau 6th Corp.Limited, Hefei, Anhui, 230011, China \\ ${ }^{3}$ Foshan Univerisity, Foshan, GuangDong, 518054, China \\ ${ }^{4}$ China Construction Steel Engineering Co. Ltd, Shenzhou, 518052, GuangDong, China
}

\begin{abstract}
With the progress of engineering technology, the ability of design and construction has been significantly improved, which the number of long-span construction and long-span Bridges and long-span steel structures are increasing more and more. As the main supporting members of Bridges and steel structures, the quality assurance of rectangular reinforced concrete independent columns is particularly important. In the implementation process of No.18 Maintenance Hangar Project of GAMECO Aircraft Maintenance Facility Phase III in Guangzhou Baiyun International Airport of China Southern Airlines, through research and practice, our company applied the subsection construction technology of super high section rectangular concrete independent columns, which can not only guarantee the quality and forming effect of the column body, but also reduce the input of formwork materials. Improve the utilization rate of formwork and scaffold effectively, and then reduce the input of turnover materials, and achieve remarkable results.
\end{abstract}

\section{Introduction}

Guangzhou Baiyun International Airport China Southern Airlines GAMECO Aircraft Maintenance Facility Phase III Maintenance Hangar Project No. 18 consists of the Hall of No. 18 Maintenance Hangar and the 4-floor Production Auxiliary Building. The structural form of hangar hall is reinforced concrete column and lattice roof. Six wide-body aircraft and five narrow-body aircraft can be placed in the hangar hall for overhaul and airline maintenance at the same time. The span is $95 m+144 m+95 m$, the depth is $107.65 m$, the building height is $44.2 \mathrm{~m}$, and the lower string elevation of the roof truss is $30 \mathrm{~m}$. The 26 large section independent columns in the hangar hall are the supporting points of the steel grid.

\section{Construction content}

In the deepening process of composite steel formwork, the combination and separation of two integral plates can be applied to independent columns of different section sizes, so that the composite steel formwork of one independent column size can be applied to independent columns of various types and sizes, and the input of steel formwork material can be reduced. The section construction of the super-high independent column ensures that the lower part is reinforced with $500 \mathrm{~mm}$ high steel formwork, and the upper part is hoisted with the combination of $5500 \mathrm{~mm}$ high steel formwork and 500mm high steel formwork, which greatly facilitates the installation and adjustment process of the steel formwork.

The overall steel formwork is quick, convenient to install and has many times of turnover use. At the same time, it is equipped with four sets of $500 \mathrm{~mm}$ high reinforced steel formwork, which can implement a set of steel formwork at the same time with three independent columns, greatly improving the use efficiency of steel formwork and greatly reducing the input of manpower and material resources[1]. The use of composite steel formwork has better bearing capacity, stiffness and stability, the concrete pouring process has little effect on the formwork verticality, concrete forming effect and good sense, can achieve the effect of plaster-free.

\section{Process principle}

\subsection{Selection of template}

(1) Formed wood template weight is small, convenient for workers to disassemble, do not rely on mechanical equipment, and wood template price is low, less cost input. The main disadvantage is that the wood formwork itself is relatively low stiffness, which is not conducive to the control of the verticality of the independent column, and the appearance of the molding is poor. In addition, the loss after repeated use is large, and it is difficult to control the

*Corresponding author: luhanwen@fosu.edu.cn 
number of turnover. And the installation efficiency is low, the progress is slow.

(2) The whole steel template is used for the molding steel die, which has large stiffness and good forming effect. And the steel die is bolted, quick installation and disassembly. Disk type steel tube scaffold erection, dismantling speed is fast, good stability. Its main drawback is that the weight of the steel die is large, and the mechanical equipment used for hoisting is large. The formalized steel die is only suitable for one size, the column section of different size needs to increase the number of steel die, and the steel die itself to design and manufacture, the cost is high. Next, dish buckle type steel tube scaffold also wants price to compare scaffold of steel tube of fastener type expensive.

(3) The combined steel die can not only guarantee the quality of the column body and the forming effect, but also has less input of formwork material compared with the standard steel die[2]. The installation and disassembly speed is fast, and the turnover can be carried out quickly[3]. With the socket type plate buckle steel pipe scaffold, the utilization rate of template and scaffold can be effectively improved,and adaptability of structure distribution is strong[4], and then the investment of turnover materials can be reduced.

Comprehensive analysis of the construction selection of combined steel mold construction.

\subsection{Selection of composite steel formwork}

Taking the No.18 Maintenance Hangar Project of GAMECO Aircraft Maintenance Facility Phase III of Guangzhou Baiyun International Airport of China Southern Airlines as an example, the total number of independent columns in the hangar hall is 26 . Column $\mathrm{Z} 1 \sim \mathrm{Z} 4$ is made of $\mathrm{C} 30$ concrete, longitudinal reinforcement is made of HRB500 steel bar, stirrup is made of HRB400 steel bar.

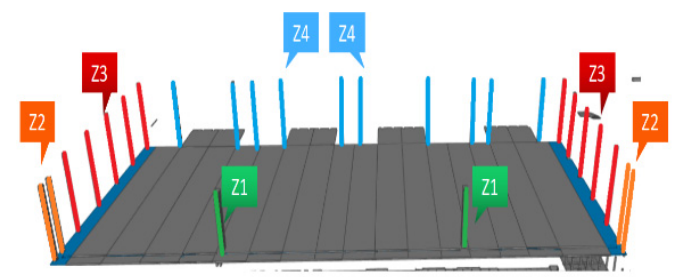

Figure 1. Schematic diagram of independent concrete column with bars

According to the calculation to determine the thickness of the steel plate, the main rib, back bar spacing and model. A piece of integral plate is formed through processing, and the four integral plates are combined to assemble the steel template of rectangular column with cross-section. The panel is made of $6 \mathrm{~mm}$ steel plate, the flange is made of $12 \times 100 \mathrm{~mm}$ flat iron, the main rib is made of $10 \#$ channel steel, the ribs are configured according to the spacing of $300 \times 300$, and the connecting hole is a long hole with a diameter of $22 \times 28$. Back carrying with $14 \#$ double channel steel, using M32 fine gadolinium rebar reinforcement, back bar spacing design is 700 .
There are 4 types of independent columns, and the largest number of them are Z3 and Z4. In the combination design of templates, a large number of templates are given priority, and two sets of templates for Z3 and Z4 are determined by comprehensively considering the impact of construction period. Then use the template of Z3 and Z4 for size design and assemble to become $\mathrm{Z} 1$ and $\mathrm{Z} 2$. The horizontal combination design is as follows:

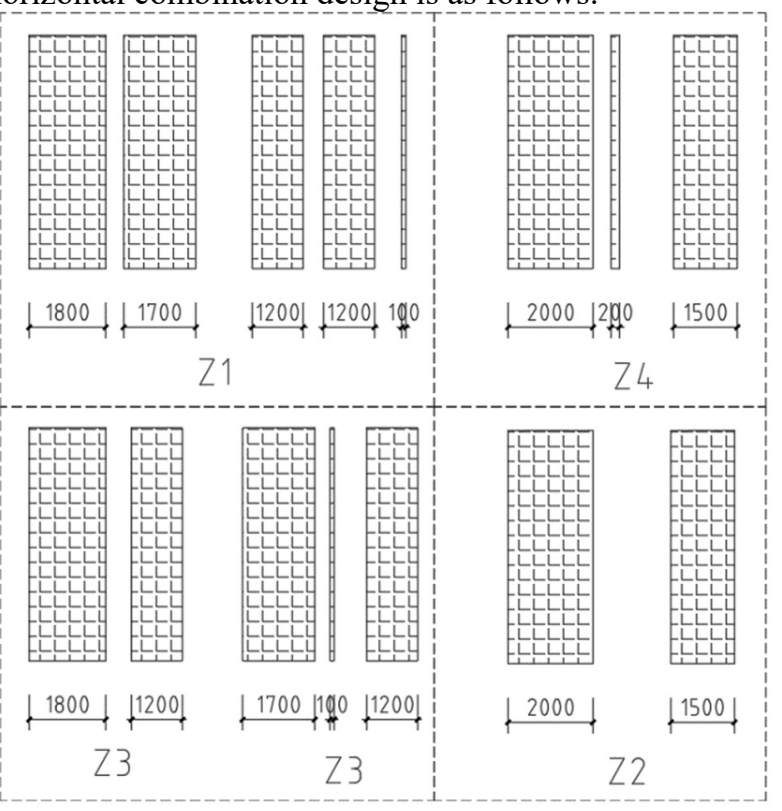

Figure 2. Horizontal combination diagram of independent column template

Through the combination of horizontal formwork, only 1 set of Z1 and 2 sets of Z4 formwork are finally needed to meet the construction schedule requirements of independent columns.

\subsection{Subsection construction of super-high section independent column}

The maximum height of the independent column is $30.13 \mathrm{~m}$, and the minimum height is $22 \mathrm{~m}$. Steel mould is used for construction. In order to ensure the forming effect and casting quality, the height of each section column should be controlled at $5-8 \mathrm{~m}$. In order to ensure the construction safety of independent columns, the operating frame shall be controlled below $8 \mathrm{~m}$. Finally, it is confirmed that the independent columns shall be divided into sections of every $6 \mathrm{~m}$ for construction. The specific sections are shown in the figure below:

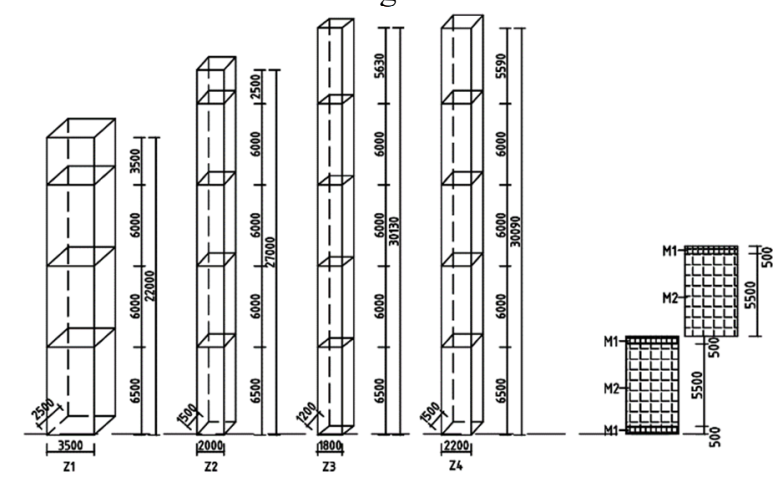

Figure 3. Schematic Diagram of Independent Column and Formwork in Vertical Segment 
In order to ensure the stability of the formwork in the concrete pouring process, the segmental construction method is adopted in the construction process. The segmental construction steel formwork is configured as $500 \mathrm{~mm}$ high steel formwork $+5500 \mathrm{~mm}$ high steel formwork $+500 \mathrm{~mm}$ high steel formwork. In section construction, it is ensured that the lower part is reinforced with $500 \mathrm{~mm}$ high steel formwork, and the upper part is hoisting the overall uncast formwork combined with $5500 \mathrm{~mm}$ high steel formwork and $500 \mathrm{~mm}$ high steel formwork. The design, configuration, construction and assembly of prefabricated components are planned with the overall concept[5].

\subsection{Verticality control of ultra-high cross section independent column}

In order to ensure the verticality of the independent column, the concrete pouring of the first section of the independent column is particularly important. Considering the difficulty of adjusting the verticality and fixing in the construction process, the first section is poured $500 \mathrm{~mm}$ high first. The vertical degree of the steel formwork is adjusted by the lifting cone in the section construction process[6], and then the four angles of the independent column are measured by the total station, and the vertical degree of the steel formwork is adjusted by the total station meter.

\section{Key points of construction}

\subsection{Deepen design of steel formwork}

(1) Considering that a set of templates and water 3 pillar of large cross section of reinforced concrete independent construction, determine the combination of steel template component model must start with the biggest crosssection of reinforced concrete column is calculated independently, ensure the steel template has enough bearing capacity, stiffness and stability, can reliably under the lateral pressure of concrete and construction load.

(2) Considering that a set of steel formwork is suitable for independent columns with different section sizes, the joint of the plate must be tight in the deepening process to prevent the concrete from forming a larger joint line, which affects the appearance of the forming.

(3) At the same time, when three independent columns are constructed with water flow, the casting height of each section is $6000 \mathrm{~mm}$. Considering that the $500 \mathrm{~mm}$ high reinforced steel formwork cannot be removed in the process of formwork transport, four sets of $500 \mathrm{~mm}$ high reinforced steel formwork must be equipped at the same time in the construction process.

\subsection{Flow construction}

Before the construction of the independent columns, a special schedule for the independent columns is arranged, and three independent columns are constructed in parallel according to a set of steel formwork, taking into account factors such as labor force, mechanical equipment and materials. After the completion of the layout of the plan, the site management and operation personnel to disclose, strictly according to the plan implementation.

Due to the characteristics of large independent column construction, a professional construction team is selected. The construction staff of this professional team are all skilled in the construction technology of reinforcing bar binding, formwork installation and concrete pouring. Therefore, each set of formwork can be assigned two groups of construction personnel, one group is specialized in reinforcing bar binding, one group is specialized in installing formwork and concrete pouring.

\subsection{Separate column section construction}

(1) In the construction of the first $500 \mathrm{~mm}$ high independent column, jack is used to straighten it. After the adjustment is completed, leveling mortar should be applied outside the root of the column. The mortar should be leveled by the ruler to avoid the leakage of slurry at the root of the column in the process of concrete pouring.

(2) The use of day pump pouring concrete, the use of hoses to extend the length of the tube into the independent column pouring, pouring height is not more than $2 \mathrm{~m}$.

(3) Correct the steel formwork. After the wire is pulled, do not remove it. In the process of pouring concrete, a special person is set to observe whether the formwork is deformed or not and adjust the formwork in time.
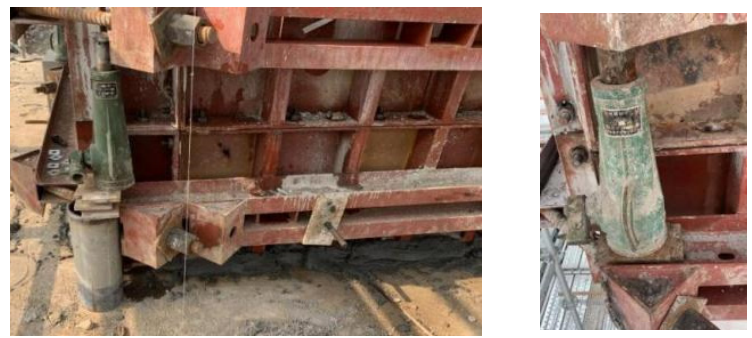

Figure 4. Adjusting perpendicularity of jack

(4) The spacing between the operating frame and the independent column structure is guaranteed to be between $600 \mathrm{~mm}$ and $800 \mathrm{~mm}$, which is convenient for the overall lifting and transportation of the steel formwork, but the next step of the construction surface must take protective measures.

(5) In the process of independent column casting, layered casting shall be carried out according to the thickness of each $300 \mathrm{~mm} \sim 400 \mathrm{~mm}$.

(6) before casting a section, the junction must be gouged.

(7) In the process of sectional casting, $500 \mathrm{~mm}$ high steel formwork must be dismantled late to serve as the supporting resting point of the formwork to be cast in the previous section, so as to facilitate the installation and adjustment of the steel formwork. 


\subsection{Verticality adjustment of independent column construction}

Hoisting the formwork to vertical hoisting steady up and down[7], the initial assembly template is adjusted by lifting cone, avoid loose shaking[8]. After the initial installation is completed, the coordinate positions of the four corner points of the independent column are measured by the total station, and the steel template is fine-tuned according to the total station data.

The position of the measuring point of the total station is unchangeable, and the measurement must be carried out in the same point until the completion of the pouring of the independent column.

The monitoring personnel must be present throughout the casting process and periodically review the position of the steel formwork.

\subsection{Steel formwork removal}

The steel formwork shall be lifted and dismantled by truck crane as a whole. In the dismantling process, the bolts shall be loosened after the steel formwork is locked by the lifting ring, and individual bolts shall not be loosened before the lifting and dismantling. In the process of lifting and dismantling, no secondary collision can be produced, so as to avoid the situation that the independent column does not lack the edge and drop the Angle.

\subsection{Mass concrete curing and temperature monitoring}

After the removal of the steel formwork, a special person shall be arranged for film mulching and watering maintenance, and the maintenance time shall not be less than 14 days.

Temperature monitoring does not need to be separately embedded temperature measuring tube, can be used to draw the screw indwilled hole temperature measurement, the heating phase send a person responsible for measuring every 2 hours, every 3 hours in the cooling phase measurement, 8 days later when the temperature difference between inside and outside measured is less than $25^{\circ}$, can stop the temperature measurement. If the temperature difference is still greater than $25^{\circ}$, continue to monitor.

\section{Quality control}

\subsection{Quality standard}

The quality standard meets the current national and industrial standards

\subsection{Quality requirements}

(1) The verticality of the template installation is allowed to deviate $10 \mathrm{~mm}$, and the field control is within $5 \mathrm{~mm}$.

(2) The position of the template mounting axis is allowed to deviate $5 \mathrm{~mm}$.
(3) the surface flatness of the template is $5 \mathrm{~mm}$, and the field control is within $2 \mathrm{~mm}$.

(4) Permissible deviation of vertical degree of independent column $\mathrm{H} / 30000+20 \mathrm{~mm}$, and field control is within $10 \mathrm{~mm}$.

(5) The allowable deviation of section size is $+10 \mathrm{~mm}$, $-5 \mathrm{~mm}$, and the field is controlled within $2 \mathrm{~mm}$.

\section{Conclusion}

Segmental construction of ultrahigh large section rectangular concrete independent column in Guangzhou Baiyun International Airport Southern Airlines GAMECO Aircraft Maintenance Facility Phase III Maintenance Hangar Project No. 18 This has greatly improved the use efficiency of steel formwork and achieved remarkable results. During the construction process, the steel formwork is hoisted as a whole, and the material utilization rate is improved, without generating additional construction waste and dust. It has good comprehensive benefits. Compared with the traditional standard composite steel formwork, the plate split assembly of the formwork can be applied to the construction of separate columns with different section sizes. This project has four independent columns with different section sizes. During the construction process, the total number of steel formwork is configured according to different section sizes, among which the steel formwork can be divided into multiple sets of steel formwork with section sizes. The traditional standard composite steel formwork needs about 53.6 tons of steel formwork materials according to the same effect. The formwork input of this project is reduced by about 20.6 tons, and the economic benefit is obviously improved. The integral steel formwork is quick, convenient to install and has many times of turnover, which can meet the requirements of 3 independent columns at the same time, greatly reducing the manpower and material input. The use of steel formwork concrete forming effect and good sense, can achieve the effect of plastering, plastering engineering quantity, unit price package labor package material greatly reduced.

\section{References}

1. WANG Jiangang. Integrated Construction Technology of Reinforced Formwork for Cast-inplace Concrete Independent Column[J]. Construction Technology, 2020,49(21):104-105+109.

2. GB/T 50214-2013, Technical code for composite steel-form[S].

3. JIANG Lu, XIE Xiaomeng. Development and Application of Prefabricated Partially Encased 
Composite Shear Wall Structure[J]. Construction Technology, 2020,49(15):22-24+37.

4. XUE Qing, LIU Dong, ZHANG Yuanzhi, ZHAO Ji, CHEN Yuhang. Technology Application of Modularized Prefabricated Super High-rise Formwork System $[\mathrm{J}]$. Construction Technology, 2019,48(08):22-26.

5. Liu lingling. Application of Aluminum Alloy Formwork in Assembly Building Construction[J]. Chinese \& Overseas Architecture, 2019(08):213-215.

6. GB 50026-2007, Code for engineering surveying[S].

7. Yao Jialiang, Xie Qichao, Yin Bo, Liu Nan. Key Control Points Analysis of Steel Formwork from Selection to the Whole Process of Hoisting[J]. Construction Technology, 2016,45(S2):633-636.

8. XIE Zhong-xin, YAO Xing-shu, CHEN Xing-you. Application of Aluminum Alloy Formwork in Assembly Construction[J]. Intelligent Building \& Smart City, 2020(09):131-132+135. 